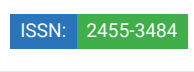

\title{
Methamphetamine-Related Psychiatric Symptoms with Special Reference to COVID-19
}

\section{Issues}

\author{
Valerie Yarema MSW ${ }^{1 *}$ and David Wellisch ${ }^{2}$ \\ ${ }^{1}$ UCLA Semel Institute for Neuroscience and Human Behavior, University of California, Los Angeles, \\ CA, USA \\ ${ }^{2}$ Department of Psychiatry \& Biobehavioral Sciences,University of California, Los Angeles, CA, USA
}

Received: 19 September, 2020
Accepted: 02 October, 2020

Published: 03 October, 2020

*Corresponding author: Valerie Yarema MSW, UCLA Semel Institute for Neuroscience and Human Behavior, University of California, Los Angeles, CA, USA, Tel: 724292-4379; E-mail: valeriegyarema@gmail.com

ORCID: https://orcid.org/0000-0003-3118-0553

Keywords: Methamphetamine use; Psychosis; Substance use; COVID-19

https://www.peertechz.com

Check for updates

\begin{abstract}
This short form review article summarizes the psychiatric symptoms associated with methamphetamine use including psychosis and places a special focus on the intersection of methamphetamine use and the COVID-19 pandemic.
\end{abstract}

\section{General psychological and physiobiological issues}

Methamphetamine is a highly addictive stimulant drug that effects the user's central nervous system. The drug enters the brain very quickly, making the substance faster-acting and more addictive than other stimulants. Methamphetamine use is associated with a plethora of both physical and psychological symptoms. Notably, the psychological symptoms related to methamphetamine use can resemble the symptoms of mental health conditions such as schizophrenia and bipolar disorder. These symptoms include psychosis, hallucinations, delusions, insomnia, irritability, and mood disturbances [13]. Methamphetamine withdrawal is accompanied by its own set of associated symptoms, including hostility, hypersomnia, aggression, fatigue, depression, and anhedonia [1,4]. The intensity of these withdrawal symptoms tends to increase as the severity and chronicity of methamphetamine use increases [4]. Research has found that psychiatric symptoms among methamphetamine users are 11 times higher than the symptoms reported by the general public [5].

\section{Methamphetamine psychosis}

Methamphetamine psychosis is one of the most common, most debilitating, and most dangerous symptoms associated with methamphetamine use [2,6-8]. Research has found that about $40 \%$ of methamphetamine users will experience psychosis [2]. Those experiencing methamphetamine psychosis most frequently endorse auditory hallucinations, tactile hallucinations, ideas of reference, paranoia, thought broadcasting, and paranoid delusions like delusions of persecution $[2,3,7,8]$. This psychosis can occur irrespective of any previous reported history of mental health issues and the symptoms associated with psychosis can result in violent as well as suicidal behavior [2,3,9]. For some individuals, methamphetamine-induced psychosis can reappear, perseverate, and resemble a primary psychotic disorder like schizophrenia [2,3]. A study by Su, et al. (2018) [8] found that $17 \%$ of the methamphetamine-abstinent users in their sample continued to experience symptoms of psychosis. Further, for users with pre-existing risk factors, methamphetamine use can lead to the onset of mental health conditions [2].

The presence of psychotic symptoms in methamphetamine users is related to a number of factors including frequency of use, chronicity of use, dosage amount, and the route of administration (i.e. whether it is smoked, snorted, taken intravenously, or ingested) $[8,10,11]$. Research by $\mathrm{Su}$, et al. (2018) [8] identified personal characteristics such as high impulsivity, previous heroin and tobacco use, and comorbid symptoms of depression and anxiety as risk factors for methamphetamine psychosis, in addition to the risk factors 
stated above. Chang, et al. (2018) [6] found that adverse life events and poly-drug use, especially the use of synthetic drugs such as ketamine, increased a methamphetamine user's risk for developing psychosis.

There are differences between primary psychosis and substance-induced psychosis. Research has compared methamphetamine-associated psychosis and refractory schizophrenia: methamphetamine users tend to exhibit similar levels of positive symptoms like delusions when compared to schizophrenia patients but score lower than those with schizophrenia for negative symptoms like blunted affect and social withdrawal $[12,13]$. Further, methamphetamine users tend to demonstrate more affective symptoms like hostility and depression than people with schizophrenia [12]. Compared to individuals diagnosed with primary psychosis, individuals diagnosed with substance-induced psychosis may be more likely to endorse suicidal ideation and may be more aware of their psychotic behaviors and thoughts [7].

\section{Treatment issues}

Mental health and medical professionals should take care to educate themselves on the psychological effects of methamphetamine use and methamphetamine withdrawal in order to properly diagnose and treat their clients, as well as identify individuals who could benefit from interventions specific to methamphetamine use. Identification of atrisk individuals is key for the critical prevention and early intervention services needed by this population, especially as the risk for deleterious impacts such as psychosis increases as the severity and chronicity of use increases $[8,10,11]$. In addition, it is important for providers to be well-versed in the effects of methamphetamines so they can provide psychoeducation about the short and long-term psychiatric consequences of methamphetamine use.

\section{Relationship to COVID-19}

The identification of methamphetamine users is especially salient during the current COVID-19 pandemic, as the pandemic may disproportionally impact this population for a number of reasons. Firstly, methamphetamine users are more likely to experience homelessness, a condition which increases the likelihood of COVID-19 transmission [14]. Secondly, evidence suggests that methamphetamine use can lead to gut-immune dysregulation that impairs immune function and makes users more susceptible to illness [15]. Further, methamphetamine use can cause pulmonary damage, pulmonary hypertension, and cardiomyopathy, which can worsen the impact of COVID-19 and an individual's prognosis [14]. Finally, during the COVID-19 pandemic, it is likely that methamphetamine users may be at a greater risk for negative outcomes such increased substance use and the onset of psychosis, due to the presence of additional life stressors including increased social isolation and greater barriers to accessing social services $[14,15]$. This risk is strengthened by the fact that social support is a vital component of the treatment of substance use disorders [14]. Currently, COVID-19 is overwhelming our healthcare system. Medical professionals may feel more stressed and have even less time to spend with patients. This new reality, coupled with the stigma associated with methamphetamine use, may lead to deleterious results for methamphetamine users [14]. Screening and assessing for methamphetamine use in a way that promotes open and honest dialogue constitutes a vital element of both obtaining comprehensive medical treatment and working to lessen the impact of COVID-19 on this marginalized population.

\section{References}

1. Courtney KE, Ray LA (2014) Methamphetamine: An update on epidemiology, pharmacology, clinical phenomenology, and treatment literature. Drug Alcohol Depend 143: 11-21. Link: https://bit.ly/36xaL6G

2. Glasner-Edwards S, Mooney LJ (2014) Methamphetamine psychosis: Epidemiology and management. CNS Drugs 28: 1115-1126. Link: https://bit.ly/2EQMZXZ

3. Radfar SR, Rawson RA (2014) Current research on methamphetamine: Epidemiology, medical and psychiatric effects, treatment, and harm reduction efforts. Addict Health 6: 146-154. Link: https://bit.ly/3imHP3U

4. Khani $Y$, Barati H, Mollajan A, Faghihi MM, Rimaz S (2018) Investigating the trend and severity of withdrawal symptoms in Methamphetamine users amongst homeless addicts. Int J High Risk Behav Addict 7: e66880. Link: https://bit.ly/3jqQp2W

5. McKetin R, McLaren J, Lubman D I, Hides L (2006) The prevalence of psychotic symptoms among methamphetamine users. Addict 101: 1473-1478. Link: https://bit.ly/2EVXTvM

6. Chang $X$, Sun $Y$, Zhang $Y$, Muhai J, Lu L, et al. (2018) A review of risk factors for methamphetamine-related psychiatric symptoms. Front Psychiatry 9: 603. Link: https://bit.ly/34kPzOy

7. Grant KM, LeVan TD, Wells SM, Li M, Stoltenberg SF, et al. (2011) Methamphetamine-associated psychosis. J Neuroimmune Pharm 7: 113-139. Link: https://bit.ly/2ShXHKh

8. Su MF, Liu MX, Li JQ, Lappin JM, Li SX, et al. (2018) Epidemiological characteristics and risk factors of methamphetamine-associated psychotic symptoms. Front Psychiatry 9: 489. Link: https://bit.ly/2GqLzE4

9. McKetin R, Lubman DI, Najman JM, Dawe S, Butterworth P, et al. (2014) Does methamphetamine use increase violent behaviour? Evidence from a prospective longitudinal study. Addict 109: 798-806. Link: https://bit.ly/3n6BBZz

10. Mcketin R, Lubman DI, Baker AL, Dawe S, Ali RL (2013) Dose-related psychotic symptoms in chronic methamphetamine users. JAMA Psychiatry 70: 319 Link: https://bit.ly/2G9Qhqc

11. Mehrjerdi ZA, Barr AM, Noroozi A (2013) Methamphetamineassociated psychosis: A new health challenge in Iran. Daru 21: 30. Link: https://bit.ly/33jlbUt

12. Panenka WJ, Procyshyn RM, Lecomte T, MacEwan GW, Flynn SW, et al. (2013) Methamphetamine use: A comprehensive review of molecular, preclinical and clinical findings. Drug Alcohol Depend 129: 167-179. Link: https://bit.ly/3cRo4Ae

13. Thomas E, Lategan H, Verster C, Kidd M, Weich L (2016) Methamphetamineinduced psychosis: Clinical features, treatment modalities and outcomes: Original research. Afr J Psychiatry (Johannesbg) 22: 980. Link: https://bit.ly/34fkUCo

14. Volkow ND (2020) Collision of the COVID-19 and addiction epidemics. Ann Intern Med 173: 61-62. Link: https://bit.ly/3iqAMXI

15. Carrico AW, Horvath KJ, Grov C, Moskowitz JT, Pahwa S, et al. (2020) Double jeopardy: Methamphetamine use and HIV as risk factors for COVID-19. AIDS Behav 7: 1-4. Link: : https://bit.ly/3jn1Rwd

Copyright: ( 2020 Valerie Yarema MSW, et al. This is an open-access article distributed under the terms of the Creative Commons Attribution License, which permits unrestricted use, distribution, and reproduction in any medium, provided the original author and source are credited.

Citation: Valerie Yarema MSW, Wellisch D (2020) Methamphetamine-Related Psychiatric Symptoms with Special Reference to CoVID-19 Issues. J Addict Med Ther Sci 6(1): 068-069. DOI: https://dx.doi.org/10.17352/2455-3484.000042 